\title{
Article \\ Effective RNAi-Mediated Silencing of the Mismatch Repair MSH2 Gene Induces Sterility of Tomato Plants but Not an Increase in Meiotic Recombination
}

\author{
Svetlana R. Strelnikova ${ }^{1, *}$, Anastasiya A. Krinitsina ${ }^{1,2}$ and Roman A. Komakhin ${ }^{1}$ \\ 1 All-Russia Research Institute of Agricultural Biotechnology, 127550 Moscow, Russia; \\ ankrina@gmail.com (A.A.K.); komakhin@gmail.com (R.A.K.) \\ 2 Biological Faculty, Lomonosov Moscow State University, 119234 Moscow, Russia \\ * Correspondence: recombination@iab.ac.ru
}

check for

updates

Citation: Strelnikova, S.R.;

Krinitsina, A.A.; Komakhin, R.A.

Effective RNAi-Mediated Silencing of

the Mismatch Repair MSH2 Gene

Induces Sterility of Tomato Plants but

Not an Increase in Meiotic

Recombination. Genes 2021, 12, 1167.

https://doi.org/10.3390/genes12081167

Academic Editors: Kejian Wang and Nico De Storme

Received: 11 June 2021

Accepted: 26 July 2021

Published: 29 July 2021

Publisher's Note: MDPI stays neutral with regard to jurisdictional claims in published maps and institutional affiliations.

Copyright: (c) 2021 by the authors. Licensee MDPI, Basel, Switzerland. This article is an open access article distributed under the terms and conditions of the Creative Commons Attribution (CC BY) license (https:/ / creativecommons.org/licenses/by/ $4.0 /)$.

\begin{abstract}
In plant breeding, the ability to manipulate meiotic recombination aids in the efficient construction of new allelic compositions of chromosomes and facilitates gene transfer from wild relatives of crop plants. The DNA mismatch repair system antagonizes meiotic recombination. In this research, a trial was conducted to evaluate transgenic tomato plants carrying an RNA interference (RNAi) construct designed to inhibit the expression of the mismatch repair $\mathrm{MSH} 2$ gene. To drive the RNAi construct, we used either a pro-SmAMP2 promoter from Stellaria media ANTIMICROBIAL PEPTIDE2 or a Cauliflower mosaic virus 35 S promoter (CaMV35S). The results of real-time PCR showed that, with a $16 \mathrm{~h}$ light $/ 8 \mathrm{~h}$ dark photoperiod, MSH2-RNAi tomato transgenic plants exhibited $\mathrm{MSH} 2$ gene transcript contents ranging from $0 \%$ to $3 \%$ in the leaves, relative to untransformed controls. However, with this lighting mode, the MSH2-RNAi transgenic plants grew slowly, flowered poorly, and did not form seed sets. During cultivation with a $12 \mathrm{~h}$ light/12 h dark photoperiod, MSH2-RNAi transgenic plants exhibited $\mathrm{MSH} 2$ gene transcript contents ranging from $3 \%$ to $42 \%$, relative to untransformed controls. Under these conditions, $\mathrm{F}_{1}$ hybrid seed sets formed for most of the MSH2-RNAi transgenic plants with the RNAi construct driven by the CaMV35S promoter, and for one transformant with the RNAi construct driven by the pro-SmAMP2 promoter. Under conditions of a $12 \mathrm{~h}$ light $/ 2 \mathrm{~h}$ dark photoperiod, most of the $\mathrm{F}_{1}$ transgenic hybrids showed $\mathrm{MSH} 2$ gene transcript contents ranging from $3 \%$ to $34 \%$ and formed $\mathrm{F}_{2}$ offspring sets, which made it possible to assess the meiotic recombination frequency. We showed that the effective inhibition of $M S H 2$ in MSH2-RNAi tomato transgenic plants is not associated with an increase in meiotic recombination compared to the control, but it stimulates the sterility of plants. It was established that the expression of the MSH2 gene in tomato plants is about 50 times higher with a $12 \mathrm{~h}$ light/12 h dark than with a $16 \mathrm{~h}$ light $/ 8 \mathrm{~h}$ dark photoperiod. It is discussed that, in Solanum lycopersicum tomato plants, which are not sensitive to the day length for flowering, changing the lighting time may be a means of controlling the meiotic recombination frequency within certain limits.
\end{abstract}

Keywords: meiosis; crossing over; $M S H 2$ gene; DNA mismatch repair; recombination; tomato

\section{Introduction}

Meiosis is a fundamental process shared by most sexually reproducing eukaryotic organisms. It generates genetic diversity through three principal mechanisms: (i) pairs of homologous chromosomes are independently sorted into haploid gametes; (ii) pairs of homologous chromosomes reciprocally exchange (crossing over) chromosome segments, altering the association of maternal and paternal alleles; and (iii) gene conversion occurs during homologous recombination [1].

In plant breeding, gaining control over the processes which alter crossing-over positions on chromosomes and increase the crossover frequency allow the more efficient construction of new allelic compositions of chromosomes for crop plants [2-4]. The ability 
to manipulate meiotic crossing over may be useful to facilitate the transmission of allelic genes from wild relatives to cultivated plants [5].

In meiosis, crossing over is triggered by the generation of double-strand breaks (DSBs) in DNA throughout the genome, and the repair of these by various biochemical pathways is necessary for the correct completion of meiosis [6]. One of the DSB repair pathways, double-strand break repair, leads to crossing over [7]. During crossing over, regions of heteroduplex DNA containing unpaired bases can locally arise between homologous chromosomes. The mismatch repair (MMR) system eliminates these regions.

The MMR system is a highly conserved pathway that exists in all organisms. The first step of mismatch recognition in eukaryotes is carried out by the homologs of prokaryotic MutS proteins, namely, MSH protein subunits. There are eight homologs of MutS in eukaryotes, MSH1 to MSH8; MSH7 is found only in plants [8] and MSH8 is found in Euglenozoa [9]. MSH proteins recognize mismatches as heterodimers; MutSa (MSH2MSH6) repairs base-base mismatches or 1-2-nucleotide insertion-deletion loops [10,11], while MutSb (MSH2-MSH3) recognizes larger insertion-deletion loops containing up to 14 nucleotides [12,13]. Plants form an additional heterodimeric complex known as MutSc (MSH2-MSH7) [8], which recognizes some base-base mismatches and reportedly plays a role in meiotic recombination [14]. The MSH2 gene is one of the key elements of MMR in plants. In meiosis, MMR is capable of destroying heteroduplex DNA and suppressing crossing over [1].

The inactivation of the $\mathrm{MSH} 2$ mismatch repair gene in interspecific yeast hybrids (Saccharomyces cerevisiae $\times$ Saccharomyces paradoxus) increases the frequency of crossing over between homeologous chromosomes and improves spore viability [15]. The knockout of the MSH2 gene (Atmsh2-1) by T-DNA insertional mutagenesis increases microsatellite instability and somatic recombination in Arabidopsis thaliana plants, indicating a decrease in the efficiency of the MMR system in plant cells [16]. In this study, it was shown that the inhibition of MMR by RNA interference (RNAi) targeting of the MSH2 gene transcript also causes microsatellite instability, but its level varies significantly in different transgenic Arabidopsis lines. Another study showed that the Atmsh2-1 mutation stably increases the frequency of meiotic recombination between marker genes against the isogenic background (Landsberg $\times$ Landsberg) of Arabidopsis, although this effect is weaker against a nonisogenic background (Columbia $\times$ Landsberg) [17]. It was recently reported that disruption in the MSH2 gene by CRISPR-Cas9 in indica rice can create genetic variability [18].

Since no knockout mutants of the $m s h 2$ gene had been found in tomatoes, strategies for the inhibition of the $\mathrm{MSH} 2$ and $M S H 7$ genes using RNAi and/or dominant-negative constructs were previously used to stimulate meiotic recombination [5]. The production of the AtMSH2-DN2 mutant protein from Arabidopsis or inhibition of the MSH7 gene transcript by RNAi allowed a modest increase in the frequency of meiotic recombination between homEologues of the S. lycopersicum tomato hybrid heterozygous for Solanum lycopersicoides Dunal chromosome 8. However, at the same time, it was found that the silencing of the $\mathrm{MSH} 2$ gene transcript by RNAi is not an effective way to increase the frequency of meiotic recombination between homEologues. In comparison with Atmsh2-1 knockout mutants of Arabidopsis and transgenic tomato plants with overexpression of AtMSH2-DN2, the absence of effects in transgenic tomato plants with $\mathrm{MSH} 2$ gene transcript silencing by RNAi could be attributed to the incomplete suppression of the MSH2 gene's expression. This being due to the use in the genetic construct of the well-known Cauliflower mosaic virus $35 \mathrm{~S}$ promoter (CaMV35S), the effectiveness of which is very limited in the floral organs of plants $[19,20]$. In addition, it is possible that the RNAi, usually targeting a region of the tomato $\mathrm{MSH} 2$ gene transcript mainly encoding the domain I of the MSH2 protein, tended to be inefficient. It also cannot be ruled out that an insufficient number of transgenic tomato lines with independent transformation events were used to assess the effect of RNAi targeted to the $M S H 2$ gene transcript on meiotic recombination. 
We previously established the nucleotide sequences encoding domains III, IV, and, partially, V of the MSH2 protein in five wild tomato species and the tomato cultivar Marglobe [21]. We found that the differences between these nucleotide sequences of the $\mathrm{MSH} 2$ gene transcripts from different species did not exceed $1 \%$; therefore, even in interspecific tomato hybrids, a single construct based on the conserved region of the tomato MSH2 gene transcript can be used for silencing by RNAi. In addition, we previously developed a new gene promoter pro-SmAMP2 from Stellaria media ANTIMICROBIAL PEPTIDE2, which, in the leaves of transgenic tobacco plants (Nicotiana tabacum L.), is 2-3 times stronger than the viral promoter CaMV35S [22,23]. The pro-SmAMP2 promoter is also effective in the floral organs of transgenic tobacco plants, including the stem, sepals, pistil, stigma, anthers, pollen, and the microsporocytes during prophase I of meiosis [24] when crossing over occurs. We hypothesized that a new genetic construct for RNAi that targets alternative regions of the $\mathrm{MSH} 2$ gene transcript and is under the control of the strong and constitutive pro-SmAMP2 promoter, would be more efficient for silencing the tomato $\mathrm{MSH} 2$ gene.

The purpose of this study was to develop an effective technique for MSH2 gene silencing by RNAi and to assess its effect on meiotic recombination between marker genes in intraspecific tomato hybrids.

\section{Materials and Methods}

\subsection{Plants for the Experiments}

In the present study, plants from the Marglobe tomato line (S. lycopersicum) with dominant alleles of the $W v$ and $D$ genes located on chromosome 2 were used. To assess the frequency of meiotic recombination, we used plants of the tomato marker line Mo938 with recessive alleles of the wv (white virescent) and $d$ (dwarf) genes on chromosome 2, linked at a frequency of about $29 \%$ [25]. The plants were cultivated in a greenhouse with a $16 \mathrm{~h}$ light $/ 8 \mathrm{~h}$ dark photoperiod at $22-24{ }^{\circ} \mathrm{C}$ unless otherwise specified. In the light period, the illuminance was $150 \mu \mathrm{mol} / \mathrm{m}^{2}$.

\subsection{Genetic Constructs for Plant Transformation}

When creating genetic plasmid constructs for Agrobacterium transformation of plants, the sequence of the MSH2 gene of the Marglobe tomato line, obtained by us previously [21], was used as a DNA template to obtain the RNAi construct. The analysis of DNA sequences was performed with the use of Basic Local Alignment Search Tool software (BLAST, https:/ /blast.ncbi.nlm.nih.gov / Blast.cgi (accessed on 20 May 2021)).

The RNAi mechanism for silencing the $\mathrm{MSH} 2$ gene transcript was created in several steps. Initially, a $963 \mathrm{bp}$ amplicon was obtained using PCR with the antM2plus and antM2minus primers (Table 1), designated as antM2.

Table 1. Primers for the creation of genetic constructs and molecular analysis of transgenic plants.

\begin{tabular}{|c|c|c|c|}
\hline Target Sequence & Primer & $5^{\prime}-3^{\prime}$ & Amplicon, bp \\
\hline \multirow{4}{*}{ MSH2 } & $\begin{array}{l}\text { antM2plus } \\
\text { antM2minus }\end{array}$ & $\begin{array}{l}\text { aagctttgatagccacttcaccaatt } \\
\text { ggatccgtttgtttgtgcaaattatg }\end{array}$ & 963 \\
\hline & $\begin{array}{l}\text { sM2plus } \\
\text { sM2minus }\end{array}$ & $\begin{array}{l}\text { aagcttagcaattatggaaactacacagtc } \\
\text { tctagagtttgtttgtgcaaattatgaatc }\end{array}$ & 662 \\
\hline & TaqMan-msh & FAMttctcttggagaggatggatcgBHQ1 & - \\
\hline & $\begin{array}{c}\mathrm{msh} 2+1 \\
\mathrm{msh} 2-1\end{array}$ & $\begin{array}{l}\text { tgcgctttccagtgttagtg } \\
\text { tgaaccactgccetcataca }\end{array}$ & 109 * \\
\hline $\begin{array}{c}\text { CaMV35S } \\
\text { pro-SmAMP2 }\end{array}$ & $\begin{array}{l}\text { E35plus } \\
\text { pSA2 }\end{array}$ & $\begin{array}{c}\text { aacaaagggtaatatccggaaacc } \\
\text { acggaattcgtaccaacgtgagtaactat }\end{array}$ & $\begin{array}{l}- \\
-\end{array}$ \\
\hline $\begin{array}{l}\text { Actin } \\
\text { (U60482) }\end{array}$ & $\begin{array}{c}\text { TaqMan-act } \\
\text { Fwd-act } \\
\text { Rev-act }\end{array}$ & [26] & $65^{*}$ \\
\hline
\end{tabular}

* The specificity of the amplification using the primer pairs was checked by electrophoresis in a $1.5 \%$ agarose gel, taking the formation of one amplicon as the criterion. 
This amplicon contained a 662 bp region necessary for the formation of an RNA double-stranded structure and a $301 \mathrm{bp}$ spacer, which played the role of a loop in the construct. Due to the sequences of the primers, the restriction sites HindIII and BamHI were used (Figure 1a).

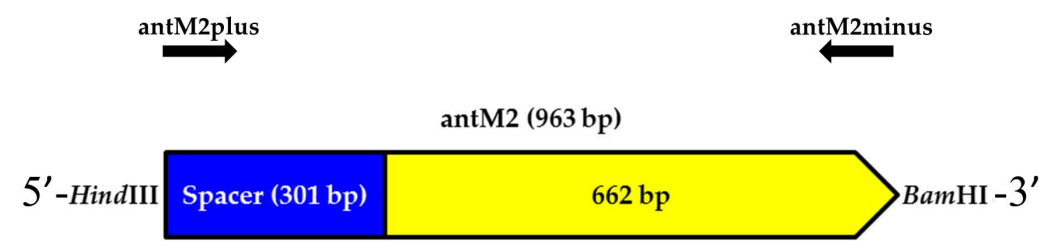

a

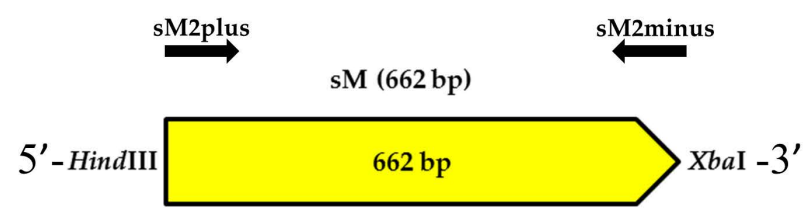

b

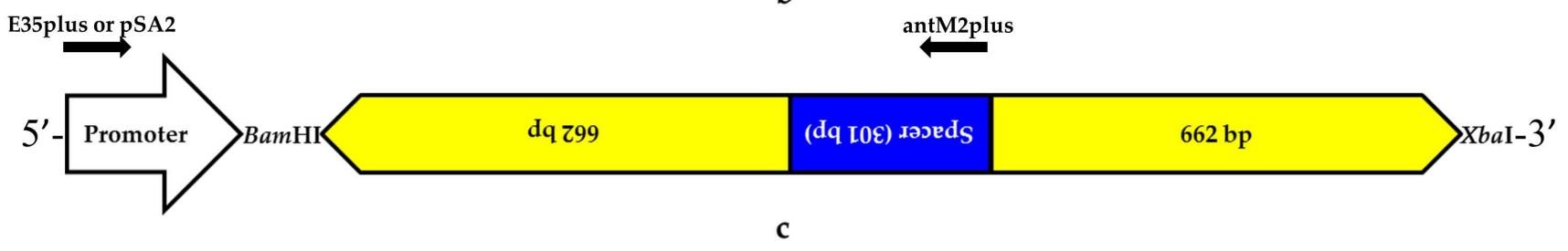

Figure 1. Genetic construct for the RNA interference targeting the MSH2 gene transcript of tomato plants. (a) Scheme of the antM2 nucleotide sequence (963 bp) including the spacer sequence (301 bp); (b) scheme of the sM2 nucleotide sequence (662 bp) complementary to $662 \mathrm{bp}$ in the antM2 sequence; (c) relative positions of the antM2 and sM2 nucleotide sequences and the gene promoter for their transcription in plant cells. Positions of the primers used for cloning and molecular analysis are shown with the black arrows; primer designations are specified above the arrows.

Then, using the PCR method and the sM2plus and sM2minus primers (Table 1), a $662 \mathrm{bp}$ amplicon partially identical to antM2 and containing HindIII and XbaI restriction sites was obtained; it was designated sM2 (Figure 1b). Both amplicons were ligated into the pGEM T-easy plasmid to form pGEM-antM2 and pGEM-sM2 plasmids. The HindIII-BamHI fragment of pGEM-antM2 was ligated into the previously created plasmid pQE-licBM2KM2-Mys25 [27] and prehydrolyzed at the same restriction sites to obtain the pQE-antM2 construct. Then, the HindIII-XbaI fragment sM2 from pGEM-sM2 was ligated into pQEantM2, which was previously hydrolyzed at the same restriction sites, to form the plasmid pQE-antM2-sM2, which contained the RNAi construct for silencing MSH2. The BamHI-XbaI fragment of pQE-antM2-sM2, which has a length of $1625 \mathrm{bp}$, was ligated into the previously created plant expression vector p35S-recA [28] and pretreated with the same enzymes. As a result, a plasmid for the Agrobacterium transformation of plants containing the functional construct antM2-sM2 under the control of the Cauliflower Mosaic Virus 35S promoter was created (CaMV 35S) (Figure 1c); it was designated p35S-antM2-sM2.

The EcoRI-BglII fragment of the previously created plasmid p822 containing the proSmAMP2 promoter from the S. media plant [24] was ligated into pQE-antM2-sM2, which was prehydrolyzed at the EcoRI and BamHI sites to obtain the plasmid pQE-pro-SmAMP2antM2-sM2. Next, the EcoRI-PstI fragment of pQE-pro-SmAMP2-antM2-sM2 was ligated into the plant expression vector $\mathrm{pCambia} 2300$ at the same sites to obtain a plasmid for Agrobacterium transformation, in which the antM2-sM2 construct was under the control of a plant-derived pro-SmAMP2 promoter. This plasmid was designated PSmAMP2-antM2sM2. The vectors p35S-antM2-sM2 and pSmAMP2-antM2-sM2 contained the neomycin 
phosphotransferase II (nptII) gene, allowing for the selection of transformed plant cells in the presence of the antibiotic kanamycin.

\subsection{Genetic Transformation of the Tomato Plants}

The Agrobacterium transformation of tomato plants was carried out as described previously [28]. The Agrobacterium tumefaciens strain AGL0, carrying the vector p35S-antM2-sM2 or pSmAMP2-antM2-sM2, was used to transform tomato plants.

\subsection{Analysis of Tomato Plants with Polymerase Chain Reaction}

For the detection of Agrobacterium contamination, previously developed primers for the VirE2 gene sequence were used [28]. To detect the hybridization region for the plasmid vectors containing the antM2-sM2 sequence and gene promoters, corresponding primers were used (Table 1). The quantitative content of the mRNA (transcript) of the MSH2 gene, with normalization relative to the Actin gene of tomato, was determined simultaneously by combining a reverse transcription reaction and real-time PCR ("in one tube"). To this end, the following components were added to the reaction mixture: TaqMan probes: ROX (5 (6) -carboxy-X-rhodamine)/BHQ2 for the Actin gene and FAM (5 (6) -carboxyfluorescein)/BHQ1 for the MSH2 gene; primers complementary to the Actin gene (Fwd-act and Rev-act) and the cDNA for the MSH2 gene transcript (msh2+1 and msh2-1); total RNA as a template; and MMLV-RT reverse transcriptase (Syntol, Moscow, Russia). The reaction temperature profile was as follows: $45^{\circ} \mathrm{C}$ for $900 \mathrm{~s} ; 95^{\circ} \mathrm{C}$ for $300 \mathrm{~s}$; 50 cycles of $95^{\circ} \mathrm{C}$ for $15 \mathrm{~s}$ and $60^{\circ} \mathrm{C}$ for $40 \mathrm{~s}$. The fluorescence level was recorded at the end of each cycle using a CFX96 Touch Real Time System amplifier (Bio-Rad, Hercules, CA, USA). The real-time PCR data were normalized using the $2^{-\Delta \Delta C T}$ method [29]. The measurements were repeated at least three times using young leaves $3.0 \pm 0.5 \mathrm{~cm}$ in length.

\subsection{RNA Extraction}

Total RNA was extracted from plant leaves using Trizol reagent (Thermo Fisher Scientific, Waltham, MA, USA) according to the instructions of the manufacturer. To eliminate genomic DNA contamination, the RNA was treated with DNase RQ1 RNase-Free (Promega, Madison, WI, USA) and stored at $-70^{\circ} \mathrm{C}$.

\subsection{Statistical Data Processing}

For statistical data processing, Student's $t$-tests were performed in Microsoft Excel. The mean values and standard deviations are presented. The statistical evaluation of phenotype segregation was carried out using the chi-square test $\left(\chi^{2}\right)$ [30]; the recombination frequency (rf) was calculated using the method of maximum likelihood [31].

\subsection{Pollen Viability}

The pollen viability of plants was assessed by acetocarmine staining, as described in [32]. Mature anthers were squashed in $1 \%$ acetocarmine in $45 \%$ glacial acetic acid, and the percentage of stained pollen grains was determined. For each plant, three anthers were squashed separately, and 100 pollen grains were scored from each anther. The results were averaged across the three anthers.

\section{Results}

3.1. Genetic Constructs Created for RNA Interference Targeting the MSH2 Gene in Tomato Plants

In our study on the silencing of $M S H 2$ by RNAi, we paid close attention to exons 4 and 5 of the $\mathrm{MSH} 2$ gene, which partially encode domain II, completely encode core domain III, and partially encode clamp domain IV of the MSH2 protein. Using the BLAST software, we made sure that this target sequence is unique in the S. lycopersicum genome. 


\subsection{Primary Transformants of Tomato Plants Created with a Reduced Content of MSH2 Gene Transcript}

The Agrobacterium transformation of the tomato Marglobe line was performed using both expression vectors, p35S-antM2-sM2 and pSmAMP2-antM2-sM2. Tomato regenerants arising from independent transformation events were selected in a growth medium containing the antibiotic kanamycin: 22 and 36 plants with the plasmids p35S-antM2-sM2 and pSmAMP2-antM2-sM2, respectively.

Using PCR and primers for the VirE2 gene, we confirmed the absence of Agrobacterium contamination in all the DNA samples from the leaves of the regenerants. Using the E35plus forward primer for the $5^{\prime}$-end of the CaMV35S promoter, the pSA2 forward primer for the $5^{\prime}$-end of the pro-SmAMP2 promoter, and the antM2plus reverse primer for the $3^{\prime}$-end of the antM2 sequence within the antM2-sM2 construct (Figure 1c), the transformants containing regions of the genetic constructs were identified among the regenerants (Figure 2).

As shown in Figure 2a, out of 22 regenerants, 17 plants were identified as transformants containing recombinant sequences from the p35S-antM2-sM2 construct with an expected length of about 1200-1300 bp. Analogously, 15 transformants with recombinant sequences from the pSmAMP2-antM2-sM2 construct with an expected length of about $1800-1900 \mathrm{bp}$, were selected from 35 regenerants (Figure $2 \mathrm{~b}$ ). The primary transformants of tomato were designated as $\mathrm{T}_{0} \mathrm{p} 35 \mathrm{~S}$-antM2 and $\mathrm{T}_{0} \mathrm{pSmAMP} 2$-antM2, and these were adapted to greenhouse conditions. However, only 11 of the 17 p35S-antM2-sM2 plants and 13 of the 15 pSmAMP2-antM2-sM2 plants were able to vegetate in the greenhouse.

To quantify the expression of the MSH2 gene by real-time PCR, a TaqMan probe was developed and designated as "msh" (Figure 3).

As shown in Figure 3, the "msh" TaqMan probe targets the MSH2 gene transcript region, which is located upstream of the target for silencing by RNAi using the antM2-sM2 construct. As a reference for measuring the $\mathrm{MSH} 2$ gene transcript level by real-time PCR (RT-PCR for the measurement of mRNAs), the "housekeeping" Actin gene for which the TaqMan probe had been previously developed was used (Table 1).

The level of the MSH2 gene transcript in tomato transformants growing for eight months in a greenhouse under "long-day" (16 h light/8 h dark) conditions was measured four times, and the mean was calculated (Figure 4).

Figure 4 shows that, under "long-day" conditions, the MSH2 gene transcript level in the young leaves of the intact tomato plants of the Marglobe line was $1.7 \pm 0.1 \times 10^{-2}$, about 60 times lower than the expression level of the Actin gene. Under the same illumination conditions, the $\mathrm{MSH} 2$ gene transcript level ranged from $1.8 \times 10^{-9}$ to $1.5 \times 10^{-2}$ among individual $\mathrm{T}_{0} \mathrm{p} 35 \mathrm{~S}-$ antM2 plants and from $1.9 \times 10^{-6}$ to $8.4 \times 10^{-2}$ among individual $\mathrm{T}_{0} \mathrm{pSm}$ AMP2-antM2 plants.

In some tomato primary transformants (designated as MSH2-RNAi plants), regardless of the genetic construct used for the RNAi, the MSH2 gene transcript level did not differ significantly from the control ( $\mathrm{T}_{0} \mathrm{p} 35 \mathrm{~S}$-antM2 Nos 9 and 10, and $\mathrm{T}_{0} \mathrm{pSm}$ AMP2-antM2 Nos $1 \_6,1 \_10$, and 22_1), and in some cases, it exceeded it ( $\left.1 \_16\right)$. Despite this, most of the $\mathrm{T}_{0} \mathrm{pSmAMP} 2$-antM2 (ca. 60\%) and $\mathrm{T}_{0} \mathrm{p} 35 \mathrm{~S}$-antM2 $(>80 \%)$ transformants demonstrated significantly lower MSH2 gene transcript levels $(p=0.05)$ than the intact Marglobe plants. In general, in these $\mathrm{T}_{0} \mathrm{p} 35 \mathrm{~S}$-antM2 plants, the residual MSH2 gene transcript content varied from $0 \%$ to $3 \%$ in comparison with the levels in intact plants. Among the $\mathrm{T}_{0} \mathrm{pSmAMP} 2$-antM2 plants, the value of this indicator ranged from $0 \%$ to $14 \%$. For the subsequent study, samples with a residual $M S H 2$ gene transcript level not exceeding $3 \%$ were also selected from $\mathrm{T}_{0} \mathrm{pSmAMP} 2$-antM2 plants. 

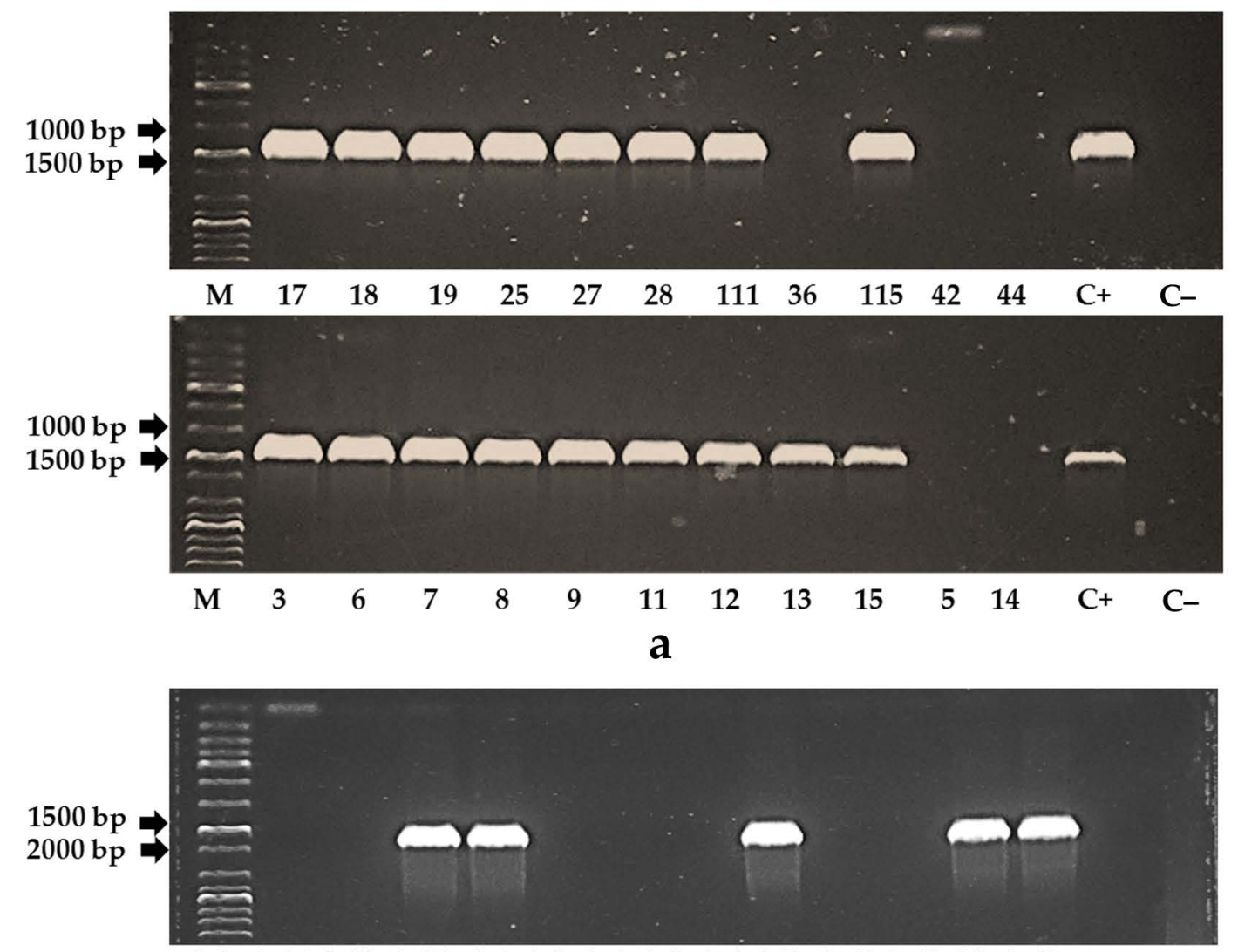

M 1_261_28 1_35 4_2 4_3 4 44 4 4_5 4 _6 4 4_7 4 4_10 4_12 22_1 C+ C-
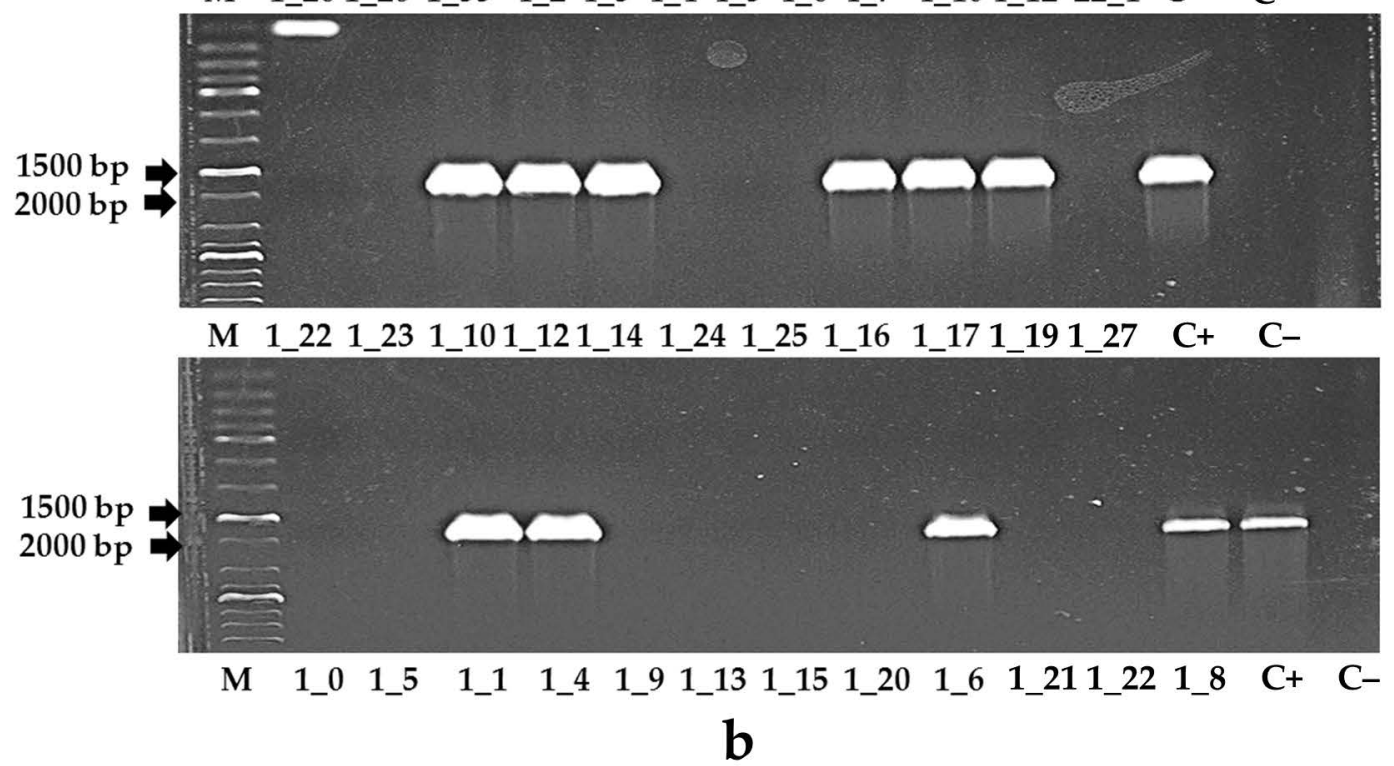

Figure 2. PCR analysis of DNA from tomato regenerants obtained using the plasmid vectors p35S-antM2-sM2 (a) and pSmAMP2-antM2-sM2 (b). The numbers below the gel images indicate the numbers of the individual transformants. "M" is a GeneRuler $1 \mathrm{~kb}$ Plus DNA Ladder (Thermo Fisher Scientific, Waltham, MA, USA). "C+" is a positive control: pSmAMP2-antM2-sM2 (a) or p35S-antM2-sM2 (b) constructs, respectively, were added as a matrix. 


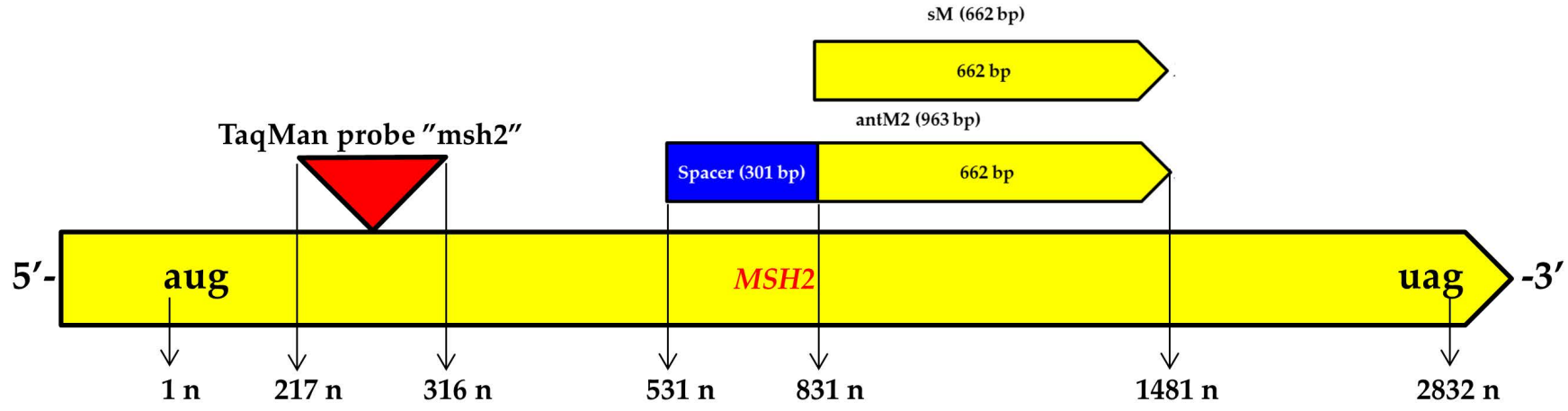

Figure 3. Scheme of the MSH2 gene transcript and target regions for RNAi and the "msh" TaqMan probe. The first nucleotide of the AUG start codon of the MSH2 gene transcript's translated region is designated $1 \mathrm{n}$; the last nucleotide of the UAG stop codon is designated $2832 \mathrm{n}$. Arrows and numbers show the relative positions of the antM2 and sM2 sequences, as well as the "msh" TaqMan probe in the MSH2 gene transcript sequence.

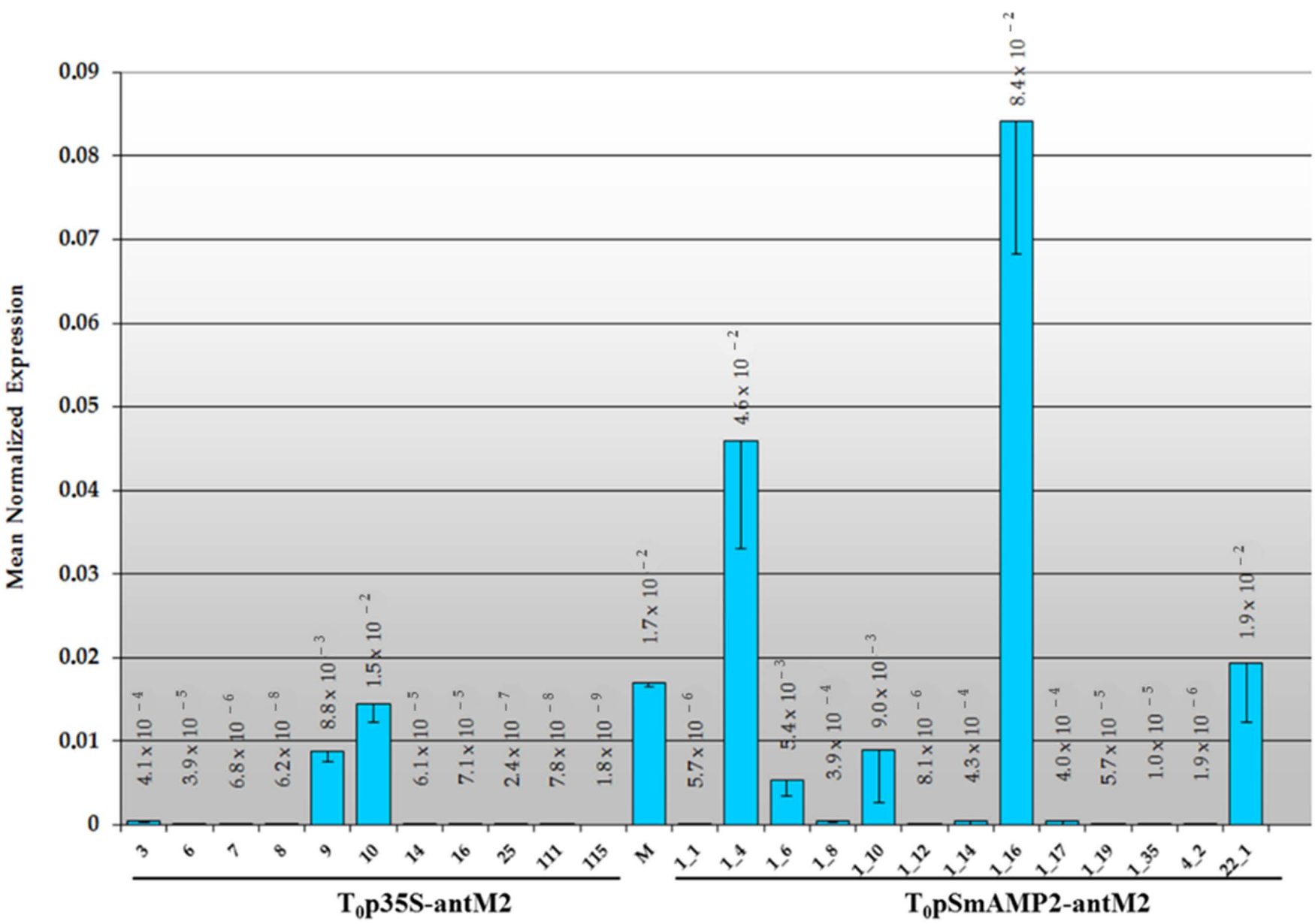

Figure 4. Expression of the MSH2 gene, normalized relative to that of the Actin gene, in tomato leaves under "long-day" (16 h light/8 h dark) conditions based on real-time PCR results. "M" means intact plants from the Marglobe line (control). The numbers below the abscissa axis show the designations of the individual transformants. The vertical lines show the standard errors.

When MSH2-RNAi tomato plants were growing under "long-day" conditions, we noticed that, compared to the intact Marglobe plants, they grew slowly, flowered poorly, and did not form fruits and seed sets as a result of self-pollination (Figure 5). 


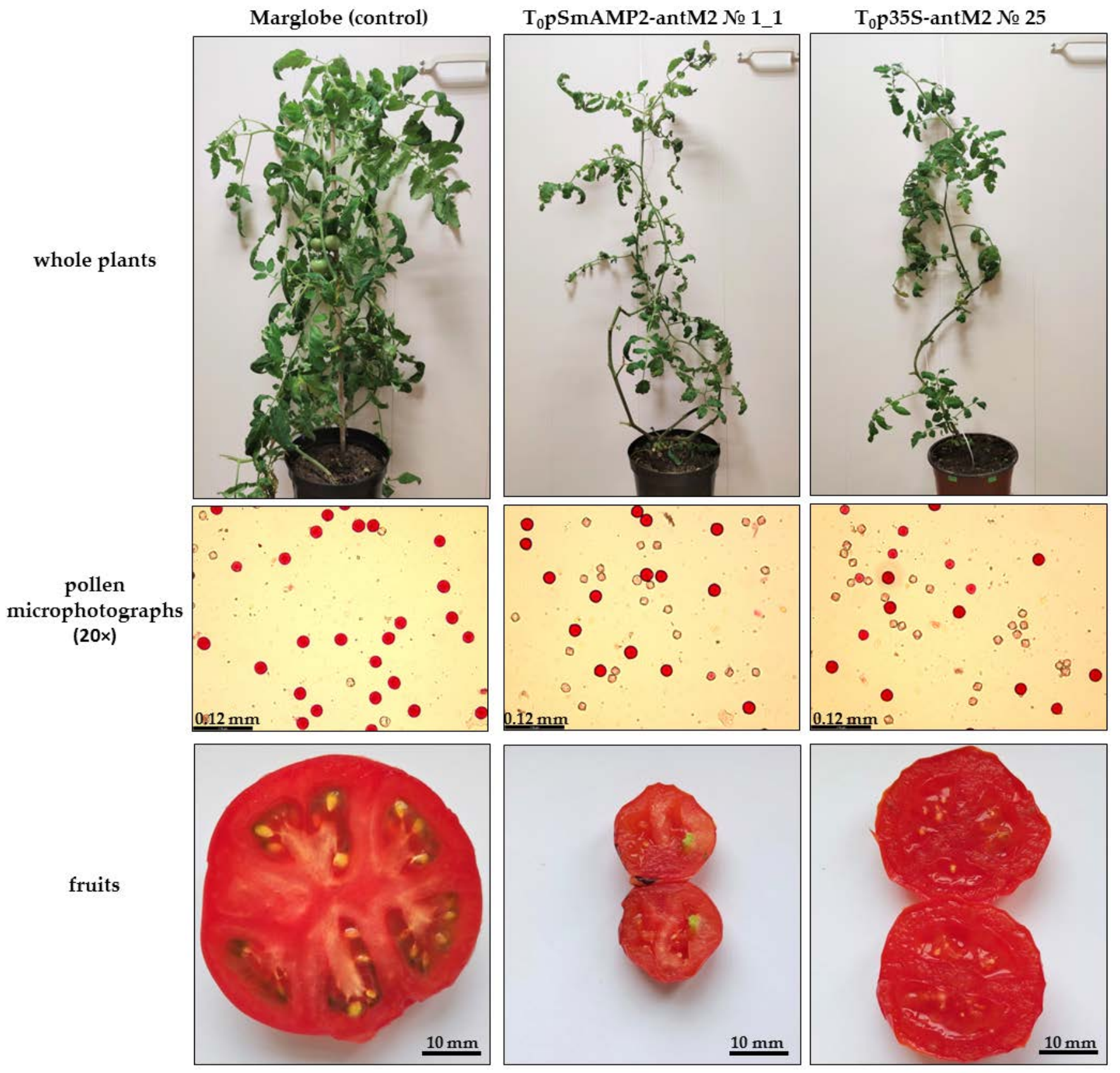

Figure 5. The morphology of several examples of MSH2-RNAi plants under "long-day" (16 h light/8 h dark) conditions.

This was unexpected, since in the individual MSH2-RNAi plants, the pollen viability according to staining with acetocarmine was at an acceptable level (from $30 \%$ to $60 \%$ ) and viable pollen grains did not differ in size and shape from pollen grains from the intact Marglobe line. Additionally, numerous attempts to pollinate them with pollen from the tomato Mo938 marker line during the year (12-13 months) failed to produce $\mathrm{F}_{1}$ hybrids from any of the $\mathrm{T}_{0} \mathrm{pSmAMP} 2$-antM2 transgenic plants. At the same time, the formation of a number of seedless fruits was noted (Figure 5). The pollination of $\mathrm{T}_{0} \mathrm{p} 35 \mathrm{~S}$-antM2 transgenic plants with Mo938 pollen made it possible to obtain fruits and viable seed sets (from 3 to 5 seeds) of $F_{1}$ hybrids only from plants Nos 3 and 16. Intact plants of the Marglobe and Mo938 lines under the same lighting conditions formed fruits with numerous seed sets from self-pollination and cross-pollination.

We changed the lighting regime from "long day" to "short day" (12 h light/12 h dark) and grew the MSH2-RNAi tomato plants for another six months. As a result, some 
transformants developed fruits from self-pollination and from pollination with pollen from the Mo938 line (Figure 6).

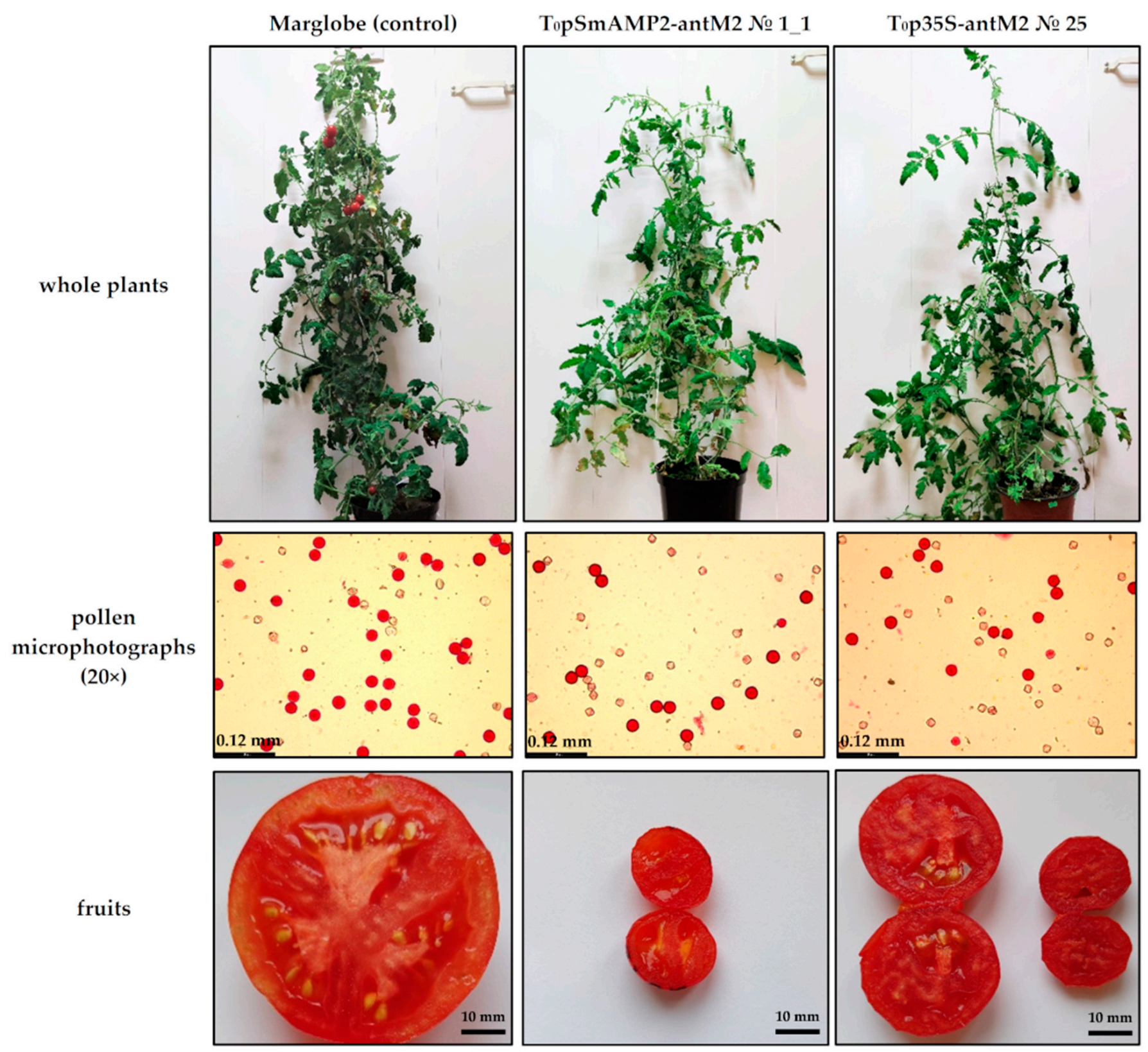

Figure 6. The morphology of several examples of MSH2-RNAi plants under "short-day" (12 h light/12 h dark) conditions.

To validate the efficiency of silencing by RNAi under "short-day" conditions, the MSH2 gene transcript levels were measured (for the first time they were measured three weeks after the lighting regime change from "long day" to "short day") in MSH2-RNAi plants from both the $\mathrm{T}_{0} \mathrm{p} 35 \mathrm{~S}$-antM2 and $\mathrm{T}_{0} \mathrm{pSmAMP2}$-antM2 groups, which formed fruits (Figure 7). 


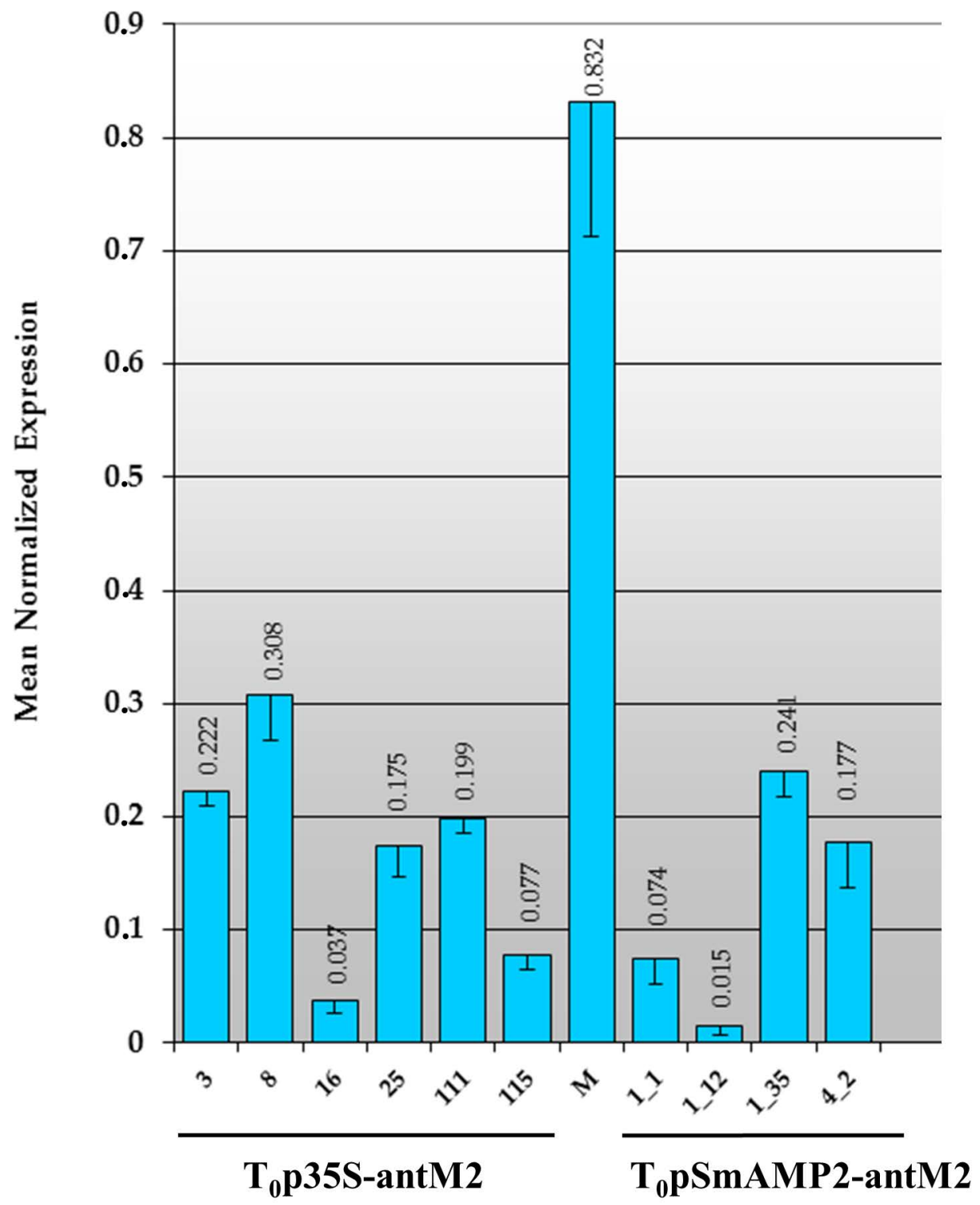

Figure 7. Expression of the $\mathrm{MSH} 2$ gene, normalized relative to that of the Actin gene, in tomato leaves under "short-day" conditions ( $12 \mathrm{~h}$ light/12 h dark) based on real-time PCR results. "M" means intact plants of the Marglobe line (control). The numbers below the abscissa axis show the designations of the individual transformants. The vertical lines show the standard errors. The average results for three measurements are presented.

Figure 7 shows that the MSH2 gene transcript level was significantly higher $(p=0.05)$ in all the plants under the "short-day" conditions than under the "long-day" conditions (Figure 4). In intact plants of the Marglobe line, the MSH2 gene transcript level increased by more than 40 times and reached $8.3 \times 10^{-1}$, while in the MSH2-RNAi plants, it increased by 50 times or more. Despite this, all of the MSH2-RNAi plants demonstrated MSH2 gene transcript levels that were significantly lower than those in the intact samples. Under "short-day" conditions, the residual expression of the $\mathrm{MSH} 2$ gene in the plant leaves varied from $5 \%$ to $42 \%$ in the $\mathrm{T}_{0} \mathrm{p} 35 \mathrm{~S}$-antM2 plants and from $3 \%$ to $32 \%$ in the $\mathrm{T}_{0} \mathrm{pSmAMP} 2$-antM2 plants. Under the "short-day" conditions, the level of the expression of the MSH2 gene in the leaves of the MSH2-RNAi plants was higher than that in the control plants under the "long-day" conditions (Figures 4 and 7).

For plant growth under "short-day" conditions, it was found that all the $\mathrm{T}_{0} \mathrm{pSmAMP2}$ antM2 transformants, with the exception of No. 4_2, still did not form seed sets upon 
self-pollination and upon pollination with pollen from the Mo938 line, although the number of seedless fruits increased. In the case of the $\mathrm{T}_{0} \mathrm{pSmAMP} 2$-antM2 transformant No. 4_2, we succeeded in obtaining several viable $F_{1}$ hybrid seed sets. We also succeeded in obtaining viable $\mathrm{F}_{1}$ hybrid seed sets from the pollination of the $\mathrm{T}_{0} \mathrm{p} 35 \mathrm{~S}$-antM2 transformants Nos 8 , 25, 111, and 115 with pollen from the Mo938 line. In addition, seed-bearing fruits were formed as a result of self-pollination in the $\mathrm{T}_{0} \mathrm{p} 35 \mathrm{~S}$-antM2 transformants Nos $3,6,16,25$, 111 , and 115 . In the last case, number of seeds in seed sets were from $3 \%$ to $10 \%$ relative to seed sets of the intact Marglobe plants. Intact plants of the Marglobe and the Mo938 lines formed fruits with numerous seed sets from self-pollination and cross-pollination under the same lighting conditions.

We failed to obtain hybrid seed sets through the pollination of Mo938 plants with the pollen of some transformants from both the $\mathrm{T}_{0} \mathrm{p} 35 \mathrm{~S}$-antM2 and $\mathrm{T}_{0} \mathrm{pSmAMP} 2$-antM2 groups; in this case, the formation of even seedless fruits was not observed.

\subsection{Assessment of the MSH2 Gene Transcript's Silencing Efficiency in Tomato Hybrids}

Most of the $\mathrm{F}_{1}$ hybrid seeds obtained by the pollination of MSH2-RNAi plants with pollen from the Mo938 line were viable. Among $\mathrm{F}_{1}$ hybrids, using PCR and primers for the fusion sequences in the p35S-antM2 and PSmAMP2-antM2 constructs (Figure 1c), we identified the segregation of $F_{1}$ plants into transgenic hybrids, which were designated as $\mathrm{F}_{1}$ p35S-antM2 or $\mathrm{F}_{1} \mathrm{pSmAMP2}$-antM2, and nontransgenic $\mathrm{F}_{1}$ hybrids. The transgenic hybrids and control (nontransgenic) hybrids were grown under "short-day" conditions to obtain the numerous $F_{2}$ offspring required for the meiotic recombination assay. During the vegetation period, expression of the $M S H 2$ gene in transgenic hybrids was quantified, while the nontransgenic hybrids were used as comparative controls (Figure 8).

It follows from the data presented in Figure 8 that $\mathrm{MSH} 2$ transcription was significantly lower in the $\mathrm{F}_{1}$ p35S-antM2 and $\mathrm{F}_{1}$ pSmAMP2-antM2 plants than in the nontransgenic $\mathrm{F}_{1}$ hybrids. On the whole, the $\mathrm{MSH} 2$ transcript level in the transgenic hybrids was comparable to that in the MSH2-RNAi plants under "short-day" conditions (Figure 7). Among all the transgenic $\mathrm{F}_{1}$ hybrids, the residual expression of the $\mathrm{MSH} 2$ gene varied from $5 \%$ to $34 \%$ in relation to the expression level in nontransgenic $F_{1}$ hybrids. By pollen staining with acetocarmine, it was found that, in all the transgenic hybrids, the level of viability varied from $65 \%$ to $87 \%$; no significant differences in this parameter between different $F_{1}$ transgenic plants during the growing season were found. In the control hybrids, the level of pollen viability was at least $91 \%$.

As a result of self-pollination, we succeeded in obtaining seed sets of the $F_{2}$ generation from only 7 out of 11 transgenic hybrids from both the $F_{1}$ p35S-antM2 and $F_{1}$ pSmAMP2antM2 plants, while only five of them had a sufficient number of offspring to assess the frequency of meiotic recombination using linked marker genes of chromosome 2. In most cases, the transgenic hybrids obtained on the basis of MSH2-RNAi plants capable of forming seed sets during self-pollination turned out to be sufficiently fertile. 


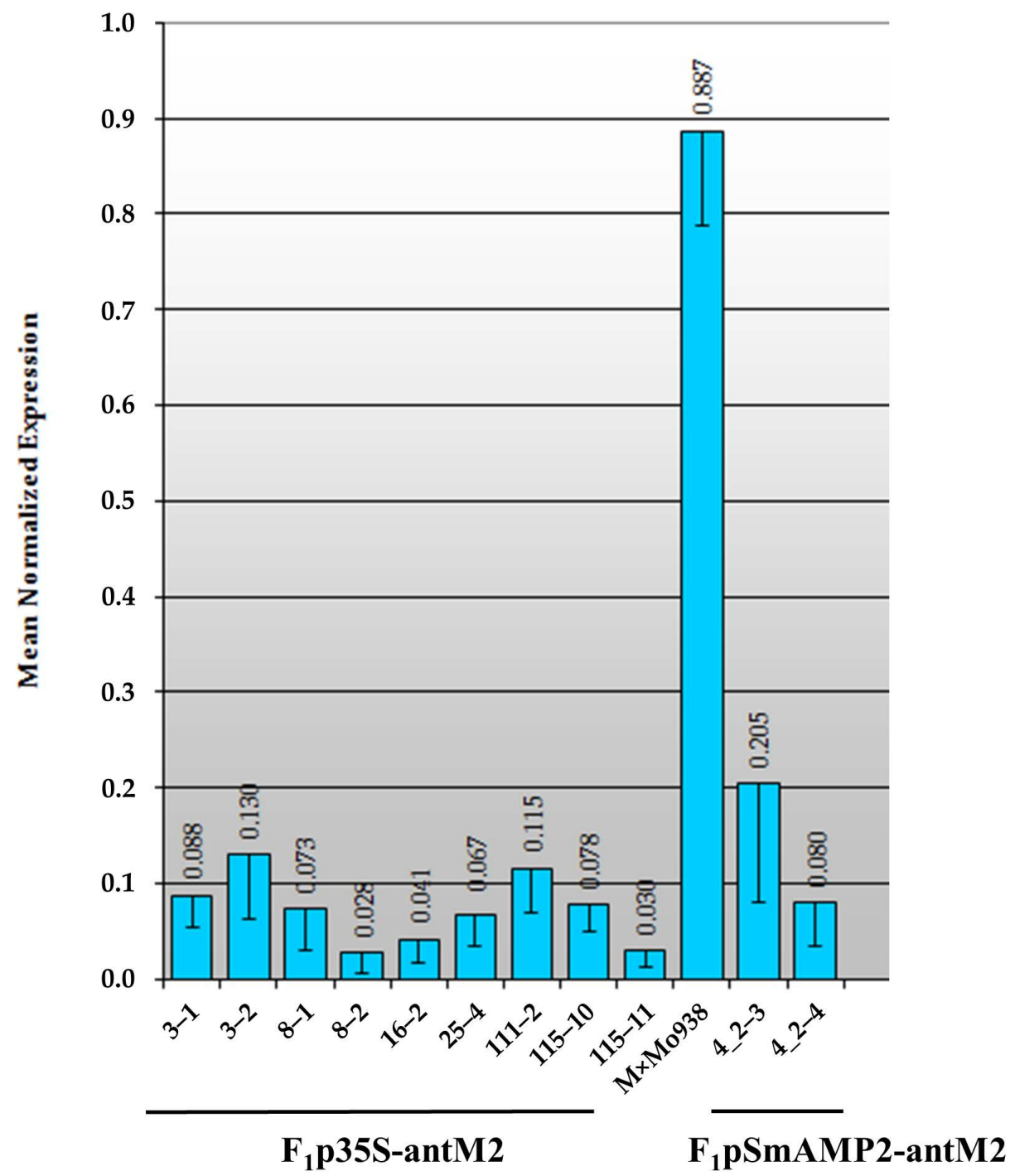

Figure 8. Expression of the $M S H 2$ gene, normalized relative to that of the Actin gene, in the leaves of tomato hybrids under "short-day" conditions ( $12 \mathrm{~h}$ light $/ 12 \mathrm{~h}$ dark) according to the results of real-time PCR. MxMo938 are nontransgenic Marglobe $\times$ Mo938 hybrids (the average values for two plants are presented). The numbers below the abscissa axis indicate the designation of individual hybrids. The vertical lines show the standard errors. The average results for three measurements over 6 months are presented.

3.4. Analysis of the Meiotic Recombination Frequency between Marker Genes of Chromosome 2 in Tomato Hybrids with the MSH2 Transcript Silenced

It was found that in the $F_{2}$ progeny from all the $F_{1}$ hybrids, only the monogenic inheritance of genes of the marker loci occurred (Table 2).

Under "short-day" conditions, the meiotic recombination frequency between the wv and $d$ genes in control $\mathrm{F}_{1}$ hybrids was $23.8 \pm 1.8 \%$ (Table 2 ), which is lower than the value of $26.7 \pm 0.4 \%$ found in $\mathrm{F}_{1}$ hybrids of the same crossing combination under "long-day" conditions [26]. However, the differences found were not statistically significant $(p=0.05)$.

In individual transgenic hybrids of the $\mathrm{F}_{1} \mathrm{p} 35 \mathrm{~S}$-antM2, the meiotic recombination frequency was within a narrow range, from $20.3 \%$ to $23.3 \%$, with an average of $22.3 \pm 0.7 \%$, which was indistinguishable from the values of the control $F_{1}$ hybrids in this experiment.

In the $\mathrm{F}_{1}$ pSmAMP2-antM2 hybrid 4-2-4, the meiotic recombination frequency was $24.6 \pm 1.0 \%$, and this did not differ from the control in this experiment. 
Table 2. Frequency of meiotic recombination (mean $\pm \mathrm{SD}$ ) between marker genes $w v$ and $d$ of chromosome 2 in tomato $\mathrm{F}_{1}$ hybrids with MSH2 silencing by RNAi under "short-day" conditions.

\begin{tabular}{|c|c|c|c|c|c|c|c|}
\hline \multirow{2}{*}{$F_{1}$ Hybrid } & \multicolumn{4}{|c|}{$F_{2}$ Phenotypic Classes } & \multicolumn{2}{|c|}{$\chi^{2}(3: 1)$} & \multirow{2}{*}{ rf, \% } \\
\hline & WvD & wvD & Wvd & wvd & Wv:wv & $\mathrm{D}: \mathrm{d}$ & \\
\hline $\mathrm{F}_{1}$ p35S-antM2 No. 3-1 & 260 & 43 & 43 & 64 & 0.26 & 0.26 & $23.3 \pm 0.2$ \\
\hline $\mathrm{F}_{1}$ p35S-antM2 No. 16-1 & 465 & 65 & 58 & 104 & 0.12 & 0.93 & $20.3 \pm 2.6$ \\
\hline $\mathrm{F}_{1}$ p35S-antM2 No. 111-2 & 261 & 40 & 35 & 58 & 0 & 0.41 & $22.5 \pm 2.2$ \\
\hline $\mathrm{F}_{1}$ p35S-antM2 No. 115-11 & 513 & 74 & 79 & 104 & 1.46 & 0.63 & $23.0 \pm 0.9$ \\
\hline Mean $\mathrm{F}_{1}$ p35S-antM2 & 1499 & 222 & 215 & 330 & 1.09 & 0.49 & $22.3 \pm 0.7$ \\
\hline $\mathrm{F}_{1} \mathrm{pSmAMP2-antM2}$ No. 4-2-4 & 536 & 85 & 93 & 114 & 0.41 & 0 & $24.6 \pm 1.0$ \\
\hline $\mathrm{F}_{1}($ Marglobe $\times$ Mo938) & 393 & 65 & 55 & 72 & 0.1 & 3.3 & $23.8 \pm 1.8$ \\
\hline
\end{tabular}

For $p \leq 0.05$ and $\mathrm{df}=1$, the critical value of $\chi^{2}$ is 3.84 .

\section{Discussion}

We included in our research eight and nine independent MSH2-RNAi tomato transgenic plants from $\mathrm{T}_{0} \mathrm{pSmAMP2}$-antM2 and $\mathrm{T}_{0} \mathrm{p} 35 \mathrm{~S}$-antM2 groups, respectively, with at least $97 \%$ RNAi silencing of the MSH2 transcript. Abnormalities in plant growth, fruit formation, and seed set were found in all MSH2-RNAi plants under "long-day" conditions. However, under "short-day" conditions similar defects (first of all, in fruit and seed set formation) were found in seven out of eight transformants from the $\mathrm{T}_{0} \mathrm{pSmAMP2}$-antM2 group and only in three out of nine transformants from the $\mathrm{T}_{0} \mathrm{p} 35 \mathrm{~S}$-antM2 group.

It was previously noted that the knockout mutation of the $\mathrm{MSH} 2$ gene in Arabidopsis plants leads to the intensive accumulation of mutations in the genome over a number of generations, partial fertility loss, and a small seed set [16,33]. Silencing the StMSH2 gene with an antisense construct or with a dominant-negative construct with a mutated AtMSH2 coding sequence led to multiple phenotypic anomalies in somatic potato hybrids [34]. No phenotypic abnormalities in growth and development were initially observed in tomato plants when the $\mathrm{MSH} 2$ and $\mathrm{MSH} 7$ genes were silenced by RNAi [5]. However, the authors of that article reported that $20 \%$ of the transformants had ploidy disorders as a result of Agrobacterium transformation, and they were not used in further research. Later, in the Arka Vikas tomato cultivar, in response to the RNAi silencing of $\mathrm{MSH} 2$ with an efficiency of more than $80 \%$, defects in the development of flowers and anthers, a low pollen viability level, tetraploid microsporocytes, low fruit productivity, and a reduced seed set were found [35]. However, in this research only one transgenic line of the three studied clearly demonstrated the phenotype described above. In addition, as noted in the Introduction, plants form a heterodimeric complex, MutSc (MSH2-MSH7) [8], which reportedly plays a role in meiotic recombination [14]. It was expected that the disruption of $\mathrm{MSH} 2$ gene function might affect the effectiveness of a heterodimeric (MSH2-MSH7) complex. Therefore, in discussion, we also pay attention to the second component of the heterodimeric complex MutSc, namely, the MSH7 protein. In particular, RNAi for the $\mathrm{MSH7}$ gene in transgenic barley plants (Hordeum vulgare L.) also exhibited a reduced seed set and pollen viability [14]. In wheat plants (Triticum aestivum L.), Tamsh7-3D mutation also reduces pollen viability but does not affect plant fertility [36]. Thus, disrupted function of the $\mathrm{MSH7}$ gene leads to similar defects as the disrupted function of $M S H 2$, i.e., reduced seed set and pollen viability. Therefore, our results are similar to most of the previously published research indicating a decrease in plant fertility and number of seeds in a seed set as a result of disruptions in the function of the $\mathrm{MSH} 2$ gene. The exact molecular mechanisms leading to the loss of fertility are not clear. Only in the research on the Arka Vikas tomato cultivar with the RNAi silencing of MSH2, did the authors attempt to interrelate the decrease of pollen viability and plant fertility with the disruptions in meiosis leading to the reduction of the seed set [35]. 
In this research, the pollen viability in the MSH2-RNAi tomato plants with at least $97 \%$ silencing of the $\mathrm{MSH} 2$ transcript by RNAi under "long-day" conditions ranged from $30 \%$ to $60 \%$. The pollen grains from MSH2-RNAi plants did not differ in size and shape from the pollen grains of the intact Marglobe plants (Figures 5 and 6). The pollen viability in the MSH2-RNAi tomato plants was comparable to the pollen viability in the tomato transgenic plants of the Marglobe line with the expression of the Escherichia coli recA gene [28]. The transgenic plants expressing the $r e c A$ gene were pollinated with pollen from the Mo938 line and formed numerous fruits and viable seed sets. Similarly, there was no difficulty in crossing tomato transgenic plants of the Marglobe line expressing SPO11 genes from yeast (Saccharomyces cerevisae) and A. thaliana, with the Mo938 line [26]. Note that we initially cultivated tomato transgenic plants with simultaneous silencing of the MSH2 gene and overexpression of SPO11 genes under "long-day" conditions. This is comparable to the results of a previously published study involving Arka Vikas MSH2-RNAi tomato lines, of which only one line with high silencing efficiency showed about $10 \%$ pollen viability, while the rest of the lines with lower silencing efficiency had a significantly higher pollen viability level [35]. However, our further results demonstrated that in MSH2-RNAi tomato plants, an acceptable level of the pollen viability is not always combined with the formation of fruits and seed sets.

In our study, the MSH2-RNAi tomato plants with at least $97 \%$ silencing of the MSH2 transcript by RNAi under "long-day" conditions, did not form seed sets after self-pollination, despite an acceptable level of pollen viability. It was previously shown that, in the Arka Vikas MSH2-RNAi tomato line with silencing (>80\%) of MSH2 by RNAi, low pollen viability $(10 \%)$ was associated with the formation of $5-10 \%$ seeds [35]. In contrast, in the Arabidopsis MSH2 mutant lines the seed set on average was reduced to only $50 \%$ [33]. In our study, only two $\mathrm{T}_{0} \mathrm{p} 35 \mathrm{~S}$-antM2 transformant plants (Nos. 3 and 16) under "long-day" conditions were able to form from 3 to 5 seeds of $F_{1}$ hybrids after pollination with Mo938 pollen; the rest did not form seeds. However, under "short-day" conditions seven more MSH2-RNAi plants with at least $60 \%$ silencing of the MSH2 transcript by RNAi were able to form $F_{1}$ hybrids seed sets. These results imply that in MSH2-RNAi tomato plants, illumination time affects the effectiveness of disruptions in the function of the MSH2.

In our study, we found, for the first time, that the expression of the MSH2 gene in the leaves of tomato plants was significantly lower when the duration of illumination was increased (Figures 4 and 7). Previously published studies do not mention the effect of the duration of illumination on the level of the $\mathrm{MSH} 2$ gene transcript in tomato plants [5,35]. Our observation itself may explain the greater efficiency of $\mathrm{MSH} 2$ gene transcript silencing by RNAi in MSH2-RNAi tomato plants under "long-day" conditions. In addition, we previously showed that the "long-day" regime increased the efficiency of the pro-SmAMP2 promoter in transgenic tobacco plants in comparison with the "short-day" regime [24]. Consequently, effective $\mathrm{MSH} 2$ gene transcript silencing by RNAi in $\mathrm{T}_{0} \mathrm{pSmAMP2}$-antM2 tomato lines was a result of a combination of these two factors. There are conflicting data regarding the efficiency of the CaMV35S promoter depending on the duration of illumination. On the one hand, it was shown that CaMV35S-directed expression was not affected by the various light conditions used [37-41]. On the other hand, some authors showed that light suppressed gene expression driven by CaMV35S [42-44]. This may be due to the improved stability of uidA mRNA in the dark $[45,46]$. One previously published study clearly showed that, when using the CaMV35S promoter to drive the uidA gene, the GUS activity in lettuce plants (Lactuca sativa L.) under a $16 \mathrm{~h} \mathrm{light} / 8 \mathrm{~h}$ dark photoperiod was significantly higher than that under $12 \mathrm{~h}$ light $/ 12 \mathrm{~h}$ dark and $8 \mathrm{~h}$ light $/ 16 \mathrm{~h}$ dark photoperiods [47]. Another study showed that the CaMV35S promoter loses its effectiveness in dark conditions in the cells of moss plants (Physcomitrella patens) [48]. Since the results of our studies show that the efficiency of $\mathrm{MSH} 2$ gene transcript silencing by RNAi with the CaMV35S promoter is higher in MSH2-RNAi tomato plants with a 
"long-day" regime, this may indicate a higher efficiency of this promoter with an increase in illumination time.

In our study, the acceptable pollen viability level and the low seed productivity of the MSH2-RNAi tomato plants when pollinated with Mo938 line pollen may also indicate defects of oocytes or failure in embryo development. Initially, in the MSH2-RNAi tomato lines, in response to the RNAi silencing of $\mathrm{MSH} 2$, the low fruit productivity and seed set were asserted to interrelate with the tetraploid microsporocytes and, as the consequence, with a pollen viability level [35]. However, the authors of this paper did not find ploidy abnormalities among the progeny of the MSH2-RNAi tomato plants and proposed that the absence of triploid progeny may also result from the existence of a strong triploid block in members of Solanaceae, including tomatoes [49,50]. In our research, the absence of ploidy abnormalities among the transgenic and control $\mathrm{F}_{1}$ hybrids confirms the monogenic inheritance of marker genes of chromosome 2 (Table 2). However, this does not completely rule out some probability of tetraploid microsporocytes formation in MSH2-RNAi tomato plants. Besides that, in mammalian cells, the $\mathrm{MSH} 2$ gene has been identified as a target of E2F transcription factors [51] wherein the loss of $\mathrm{MSH} 2$ function thus inhibits E2F signaling. It is believed that disruption of E2F signaling affects the progression of the cell cycle and promotes failure of cytokinesis. As the $\mathrm{MSH} 2$ gene has a probable role in the mammalian cell cycle, it is supposed plausible that $M S H 2$ may affect the cell cycle in plants in a similar fashion [35]. It was shown that the Cd-induced G2/M phase arrest was markedly diminished in MSH2-deficient Arabidopsis roots [52]. Furthermore, Cd elicited endoreplication in MSH2-deficient roots. The results suggest that $\mathrm{MSH} 2$ components of the MMR system are involved in the G2 phase arrest and endoreplication in Arabidopsis roots. These results do not rule out that in our research the low fertility of MSH2-RNAi tomato plants might also be related to disruptions in the G2/M phase during pollination, impregnation or embryo development. In our research, the formation of a number of seedless fruits in MSH2-RNAi tomato plants resulting from pollination with the Mo938 line pollen, may be seen as evidence of the above supposition.

The similar phenotypic abnormalities identified in MSH2-RNAi tomato plants in our research and in a previously published study [35] may also be due to the selection of the same target regions in the $\mathrm{MSH} 2$ gene transcript sequence for silencing by RNAi. Previously, the sequence from 416 to $717 \mathrm{n}$ (relative to the AUG start codon) of the translated region of the $\mathrm{MSH} 2 \mathrm{mRNA}$ was used for silencing by RNAi [35]. In our research, the main target for RNAi was the sequence from 831 to $1481 \mathrm{n}$ and, in addition, the region from 531 to $831 \mathrm{n}$, which plays the role of a spacer in the antM2-sM2 construct for RNAi, could also participate in the suppression of $\mathrm{MSH} 2$ gene expression as an antisense construct (Figure 3). Thus, in both tomato studies, the MSH2 region between 531 and $717 \mathrm{n}$ was subject to silencing. Therefore, it cannot be ruled out that the high efficiency of $\mathrm{MSH} 2$ gene silencing and its phenotypic consequences depend on the $\mathrm{MSH} 2$ gene transcript region used as a target for RNAi. Notably, in the first study published on MSH2 silencing by RNAi, which did not mention phenotypic abnormalities in tomato hybrids, the target was a sequence from 55 to $437 \mathrm{n}$ in the $\mathrm{MSH} 2 \mathrm{mRNA}$ [5]. At the same time, in the latter study, the limited number of MSH2-RNAi lines, the use of the viral CaMV35S promoter, and the lack of quantitative determination of $\mathrm{MSH} 2$ gene expression could have hindered the involvement of MSH2-RNAi lines with highly efficient RNAi silencing in the studies. Though we did not find in the S. lycopersicum genome other targets for the antM2-sM2 construct for RNAi, the defects in MSH2-RNAi plant growth may evidence their existence. Alternatively, one can suppose a more significant role of the $\mathrm{MSH} 2$ gene in the course of vegetative development of the tomato plants.

In our research, the plant-derived pro-SmAMP2 promoter and the virus-derived CaMV35 promoter were comparable in terms of the effectiveness of MSH2 silencing in tomato leaves under two different lighting conditions (Figures 4, 7 and 8). However, the use of the plant-derived promoter further reduced the ability of MSH2-RNAi plants to form fruits and seed sets. The inability to obtain any progeny from MSH2-RNAi plants 
with the pro-SmAMP2 promoter in this study may indicate a higher efficiency for the silencing of $\mathrm{MSH} 2$ in floral organs and their constituent tissues compared to when the CaMV35S promoter is used. Although under the "short-day" conditions, the level of the expression of the MSH2 gene in the leaves of the MSH2-RNAi plants was higher than that in the control plants under the "long-day" conditions (Figures 4 and 7), most $\mathrm{T}_{0} \mathrm{pSm} A M P 2-a n t M 2$ plants remained sterile. The higher efficiency of the pro-SmAMP2 promoter is a consequence of a stable pattern of transgene expression under its control, which encompasses all of the organs studied in transgenic plants, including floral organs, microsporocytes, and pollen [24]. We also previously found that the high expression level of the $u i d A$ reporter gene driven by the pro-SmAMP2 promoter is comparable in the leaves and anthers of transgenic tobacco plants and is only two times lower in pollen (unpublished data). The ability of one MSH2-RNAi plant (No. 4_2) from the TopSmAMP2-antM2 group to form seed sets can be explained by the integration of T-DNA into the genome region, which limits the efficiency of the pro-SmAMP2 promoter under "short-day" conditions in floral organs but not in leaves. Unlike the pro-SmAMP2 promoter, the CaMV35S viral promoter is significantly less efficient in the floral organs of plants [19]. In particular, the expression pattern of the uidA reporter gene driven by the CaMV35S promoter did not include pollen in $43 \%$ of the transformants, and in the remaining $57 \%$, the reporter level was 1-2 orders of magnitude lower than that in the leaves. The observed pattern of the CaMV35S viral promoter's expression in the floral organs of the transgenic plants explain why, in this study, only three out of nine $\mathrm{T}_{0} \mathrm{p} 35 \mathrm{~S}$-antM2 tomato plants showed phenotypic abnormalities in fruit and seed set development, while the other six out of nine $\mathrm{T}_{0} \mathrm{p} 35 \mathrm{~S}$ antM2 tomato plants formed the expected seed set, and their hybrids had an acceptable meiotic recombination level (Table 2). It is probable that, in the MSH2-RNAi plants without phenotypic abnormalities and their $F_{1}$ hybrids, the efficiency of the CaMV35S promoter in the floral organs was zero or low.

In this research, the meiotic recombination in control $\mathrm{F}_{1}$ hybrids under "short-day" conditions was lower (Table 2) than that seen previously in similar control $\mathrm{F}_{1}$ hybrids under "long-day" conditions [26]. In the context of a decrease in the expression of the MSH2 gene under "long-day" conditions, these results do not contradict the initial assumption that a decrease in MSH2 expression has a positive effect on meiotic recombination. Perhaps, in tomato plants that are not sensitive to the day length for flowering, changing the lighting time may be a trigger influencing meiotic recombination within certain limits.

In our study, under "short-day" conditions we obtained an insignificant decrease in the meiotic recombination between the marker genes $w v$ and $d$ of chromosome 2 in $\mathrm{F}_{1}$ hybrids with $\mathrm{MSH} 2$ silencing when using the CaMV35S promoter, relative to the meiotic recombination in the nontransgenic control (Table 2). Previously, in tomato hybrids, when the MSH2 gene was silenced by RNAi using the CaMV35S viral promoter, slight decreases in the genetic distances between markers were also observed [5]. The similarity of the results obtained in the two studies may be due to the fact that only plants with low RNAi efficiency in the floral organs were used to estimate the frequency of meiotic recombination. In the previous study, for the assessment of genetic distances, the authors selected MSH2RNAi tomato lines that did not have phenotypic abnormalities and, thus, probably excluded transgenic plants with high MSH2 gene silencing efficiency from their studies [5]. In our study, the selection of plants with low RNAi efficiency occurred naturally when using the CaMV35S promoter to assess meiotic recombination, since the MSH2-RNAi tomato plants with high MSH2 silencing efficiency were sterile. The lack of effects in one hybrid, No. $4 \_2-2$, from the $\mathrm{T}_{0} \mathrm{pSm} A M P 2$-antM2 group, as mentioned above, may have been caused by a decrease in the efficiency of the pSmAMP2 promoter due to the integration of T-DNA into a specific region of the tomato genome.

Altogether, these results indicate that, in tomato plants, $M S H 2$ silencing by RNAi to increase the meiotic recombination frequency has certain limitations. There is probably a certain level of $\mathrm{MSH} 2$ gene expression that is critical for the viability of tomato plants. This 
may be the reason why $\mathrm{MSH} 2$ gene knockout mutants were not found among the various tomato species.

Author Contributions: Conceptualization and methodology, R.A.K.; validation, R.A.K., S.R.S., and A.A.K.; formal analysis, S.R.S. and A.A.K.; investigation, R.A.K., S.R.S., and A.A.K.; data curation, R.A.K., S.R.S., and A.A.K.; visualization, R.A.K.; writing-original draft preparation and review and editing, R.A.K., S.R.S., and A.A.K.; supervision, project administration, resources, and funding acquisition, R.A.K. All authors have read and agreed to the published version of the manuscript.

Funding: The construction of transgenic plants with the pro-SmAMP2 promoter was supported by the Russian Foundation for Basic Research (grant no. 19-016-00067); the construction of transgenic plants with the CaMV35S promoter was carried out within the framework of the state contract no. 0574-2019-0001 (state registration no. AAAA-A18-118051890110-1).

Institutional Review Board Statement: Not applicable.

Informed Consent Statement: Not applicable.

Data Availability Statement: The data presented in this study are available on request from the corresponding author.

Conflicts of Interest: The authors declare no conflict of interest.

\section{References}

1. Cole, F.; Keeney, S.; Jasin, M. Preaching about the Converted: How Meiotic Gene Conversion Influences Genomic Diversity. Ann. N. Y. Acad. Sci. 2012, 1267, 95-102. [CrossRef] [PubMed]

2. De Muyt, A.; Pereira, L.; Vezon, D.; Chelysheva, L.; Gendrot, G.; Chambon, A.; Lainé-Choinard, S.; Pelletier, G.; Mercier, R.; Nogué, F.; et al. A High Throughput Genetic Screen Identifies New Early Meiotic Recombination Functions in Arabidopsis thaliana. PLoS Genet. 2009, 5, e1000654. [CrossRef] [PubMed]

3. Wijnker, E.; de Jong, H. Managing Meiotic Recombination in Plant Breeding. Trends Plant Sci. 2008, 13, 640-646. [CrossRef] [PubMed]

4. Lambing, C.; Franklin, F.C.H.; Wang, C.-J.R. Understanding and Manipulating Meiotic Recombination in Plants. Plant Physiol. 2017, 173, 1530-1542. [CrossRef] [PubMed]

5. Tam, S.M.; Hays, J.B.; Chetelat, R.T. Effects of Suppressing the DNA Mismatch Repair System on Homeologous Recombination in Tomato. Theor. Appl. Genet. 2011, 123, 1445-1458. [CrossRef] [PubMed]

6. Mézard, C.; Tagliaro Jahns, M.; Grelon, M. Where to Cross? New Insights into the Location of Meiotic Crossovers. Trends Genet. 2015, 31, 393-401. [CrossRef]

7. Page, S.L.; Hawley, R.S. Chromosome Choreography: The Meiotic Ballet. Science 2003, 301, 785-789. [CrossRef]

8. Culligan, K.M.; Hays, J.B. Arabidopsis MutS Homologs-AtMSH2, AtMSH3, AtMSH6, and a Novel AtMSH7-Form Three Distinct Protein Heterodimers with Different Specificities for Mismatched DNA. Plant Cell 2000, 12, 991-1002. [CrossRef]

9. Sachadyn, P. Conservation and Diversity of MutS Proteins. Mutat. Res./Fundam. Mol. Mech. Mutagen. 2010, 694, 20-30. [CrossRef]

10. Acharya, S.; Wilson, T.; Gradia, S.; Kane, M.F.; Guerrette, S.; Marsischky, G.T.; Kolodner, R.; Fishel, R. HMSH2 Forms Specific Mispair-Binding Complexes with HMSH3 and HMSH6. Proc. Natl. Acad. Sci. USA 1996, 93, 13629-13634. [CrossRef]

11. Genschel, J.; Littman, S.J.; Drummond, J.T.; Modrich, P. Isolation of MutS $\beta$ from Human Cells and Comparison of the Mismatch Repair Specificities of MutS $\beta$ and MutS $\alpha$. J. Biol. Chem. 1998, 273, 19895-19901. [CrossRef]

12. Marti, T.M.; Kunz, C.; Fleck, O. DNA Mismatch Repair and Mutation Avoidance Pathways. J. Cell. Physiol. 2002, 191, 28-41. [CrossRef]

13. Modrich, P. Mechanisms and Biological Effects of Mismatch Repair. Annu. Rev. Genet. 1991, 25, 229-253. [CrossRef] [PubMed]

14. Lloyd, A.H.; Milligan, A.S.; Langridge, P.; Able, J.A. TaMSH7: A Cereal Mismatch Repair Gene That Affects Fertility in Transgenic Barley (Hordeum vulgare L.). BMC Plant Biol. 2007, 7, 67. [CrossRef] [PubMed]

15. Hunter, N.; Chambers, S.R.; Louis, E.J.; Borts, R.H. The mismatch repair system contributes to meiotic sterility in an interspecific yeast hybrid. EMBO J. 1996, 15, 1726-1733. [CrossRef] [PubMed]

16. Leonard, J.M.; Bollmann, S.R.; Hays, J.B. Reduction of Stability of Arabidopsis Genomic and Transgenic DNA-Repeat Sequences (Microsatellites) by Inactivation of AtMSH2 Mismatch-Repair Function. Plant Physiol. 2003, 133, 328-338. [CrossRef] [PubMed]

17. Emmanuel, E.; Yehuda, E.; Melamed-Bessudo, C.; Avivi-Ragolsky, N.; Levy, A.A. The Role of AtMSH2 in Homologous Recombination in Arabidopsis thaliana. EMBO Rep. 2006, 7, 100-105. [CrossRef] [PubMed]

18. Karthika, V.; Chandrashekar, B.K.; Kiranmai, K.; Ag, S.; Makarla, U.; Ramu, V.S. Disruption in the DNA Mismatch Repair Gene MSH2 by CRISPR-Cas9 in Indica Rice Can Create Genetic Variability. J. Agric. Food Chem. 2021, 69, 4144-4152. [CrossRef]

19. Wilkinson, J.E.; Twell, D.; Lindsey, K. Activities of CaMV 35 S and Nos Promoters in Pollen: Implications for Field Release of Transgenic Plants. J. Exp. Bot. 1997, 48, 265-275. [CrossRef] 
20. Sunilkumar, G.; Mohr, L.; Lopata-Finch, E.; Emani, C.; Rathore, K.S. Developmental and Tissue-Specific Expression of CaMV 35S Promoter in Cotton as Revealed by GFP. Plant Mol. Biol. 2002, 50, 463-479. [CrossRef]

21. Krinitsina, A.; Komakhin, R. Cloning of the Mismatch Repair MSH2 Gene Fragment from Various Tomato Species. Biomics 2019, 10, 336-343. [CrossRef]

22. Madzharova, N.V.; Kazakova, K.A.; Strelnikova, S.R.; Snycheva, O.A.; Vetchinkina, E.M.; Efremova, L.N.; Vysotskii, D.A.; Babakov, A.V.; Komakhin, R.A. Promoters Pro-SmAMP1 and pro-SmAMP2 from Wild Plant Stellaria media for the Biotechnology of Dicotyledons. Russ. J. Plant Physiol. 2018, 65, 750-761. [CrossRef]

23. Efremova, L.N.; Strelnikova, S.R.; Gazizova, G.R.; Minkina, E.A.; Komakhin, R.A. A Synthetic Strong and Constitutive Promoter Derived from the Stellaria media Pro-SmAMP1 and pro-SmAMP2 Promoters for Effective Transgene Expression in Plants. Genes 2020, 11, 1407. [CrossRef] [PubMed]

24. Komakhin, R.A.; Vysotskii, D.A.; Shukurov, R.R.; Voblikova, V.D.; Komakhina, V.V.; Strelnikova, S.R.; Vetchinkina, E.M.; Babakov, A.V. Novel Strong Promoter of Antimicrobial Peptides Gene Pro-SmAMP2 from Chickweed (Stellaria media). BMC Biotechnol. 2016, 16, 43. [CrossRef]

25. Komakhin, R.A.; Strelnikova, S.R.; Zhuchenko, A.A. Genetic Features of the Tomato Marker Line Mo938. Russ. J. Genet. 2019, 55, 52-60. [CrossRef]

26. Komakhina, V.V.; Krinitsina, A.A.; Milyukova, N.A.; Komakhin, R.A. Expression of Recombinant SPO11 Genes Locally Alters Crossing over in Tomato. Russ. J. Genet. 2020, 56, 1079-1089. [CrossRef]

27. Komakhin, R.A.; Abdeeva, I.A.; Salehi Dzhuzani, G.R.; Goldenkova, I.V.; Zhuchenko, A.A. Thermostable Lichenase as a Translational Reporter. Russ. J. Genet. 2005, 41, 23-31. [CrossRef]

28. Komakhin, R.A.; Komakhina, V.V.; Milyukova, N.A.; Goldenkova-Pavlova, I.V.; Fadina, O.A.; Zhuchenko, A.A. Transgenic Tomato Plants Expressing RecA and NLS-RecA-LicBM3 Genes as a Model for Studying Meiotic Recombination. Russ. J. Genet. 2010, 46, 1440-1448. [CrossRef]

29. Muller, P.Y.; Miserez, A.R.; Dobbie, Z. Processing of Gene Expression Data Generated by Quantitative Real-Time RT-PCR. BioTechniques 2002, 32, 6 .

30. Suzuki, D.T.; Griffiths, A.J.F. Introduction to Genetic Analysis; W. H. Freeman: New York, NY, USA, 1976.

31. Kosambi, D.D. The Estimation of Map Distances from Recombination Values. In Selected Works in Mathematics and Statistics; Ramaswamy, R., Ed.; Springer: New Delhi, India, 2016; pp. 125-130. ISBN 978-81-322-3676-4.

32. Chetelat, R.T. Overcoming Sterility and Unilateral Incompatibility of Solanum lycopersicum $\times$ S. sitiens Hybrids. Euphytica 2016, 207, 319-330. [CrossRef]

33. Hoffman, P.D.; Leonard, J.M.; Lindberg, G.E.; Bollmann, S.R.; Hays, J.B. Rapid Accumulation of Mutations during Seed-to-Seed Propagation of Mismatch-Repair-Defective Arabidopsis. Genes Dev. 2004, 18, 2676-2685. [CrossRef]

34. Rakosy-Tican, E.; Lörincz-Besenyei, E.; Molnár, I.; Thieme, R.; Hartung, F.; Sprink, T.; Antonova, O.; Famelaer, I.; Angenon, G.; Aurori, A. New Phenotypes of Potato Co-Induced by Mismatch Repair Deficiency and Somatic Hybridization. Front. Plant Sci. 2019, 10, 3. [CrossRef]

35. Sarma, S.; Pandey, A.K.; Sharma, K.; Ravi, M.; Sreelakshmi, Y.; Sharma, R. MutS-Homolog2 Silencing Generates Tetraploid Meiocytes in Tomato (Solanum lycopersicum). Plant Direct 2018, 2, e00017. [CrossRef]

36. Serra, H.; Svačina, R.; Baumann, U.; Whitford, R.; Sutton, T.; Bartoš, J.; Sourdille, P. Ph2 encodes the mismatch repair protein MSH7-3D that inhibits wheat homoeologous recombination. Nat. Commun. 2021, 12, 803. [CrossRef] [PubMed]

37. Frohnmeyer, H.; Hahlbrock, K.; Schafer, E. A Light-Responsive in Vitro Transcription System from Evacuolated Parsley Protoplasts. Plant J. 1994, 5, 437-449. [CrossRef]

38. Cooker, D.E.; Webb, K.J. Stability of CaMV 35S-Gus Gene Expression in (Bird's Foot Trefoil) Hairy Root Cultures under Different Growth Conditions. Plant Cell Tissue Organ Cult. 1997, 47, 163-168. [CrossRef]

39. Yamamoto, Y.Y.; Kondo, Y.; Kato, A.; Tsuji, H.; Obokata, J. Light-Responsive Elements of the Tobacco PSI-D Gene Are Located Both Upstream and within the Transcribed Region. Plant J. 1997, 12, 255-265. [CrossRef] [PubMed]

40. Kurata, H.; Takemura, T.; Furusaki, S.; Kado, C.I. Light-Controlled Expression of a Foreign Gene Using the Chalcone Synthase Promoter in Tobacco BY-2 Cells. J. Ferment. Bioeng. 1998, 86, 317-323. [CrossRef]

41. Zambre, M.; Terryn, N.; De Clercq, J.; De Buck, S.; Dillen, W.; Van Montagu, M.; Van Der Straeten, D.; Angenon, G. Light Strongly Promotes Gene Transfer from Agrobacterium tumefaciens to Plant Cells. Planta 2003, 216, 580-586. [CrossRef]

42. Ellis, D.D.; McCabe, D.; Russell, D.; Martinell, B.; McCown, B.H. Expression of Inducible Angiosperm Promoters in a Gymnosperm, Picea Glauca (White Spruce). Plant Mol. Biol. 1991, 17, 19-27. [CrossRef]

43. Schnurr, J.A.; Guerra, D.J. The CaMV-35S Promoter Is Sensitive to Shortened Photoperiod in Transgenic Tobacco. Plant Cell Rep. 2000, 19, 279-282. [CrossRef] [PubMed]

44. Zuker, A.; Ahroni, A.; Tzfira, T.; Ben-Meir, H.; Vainstein, A. Wounding by Bombardment Yields Highly Efficient AgrobacteriumMediated Transformation of Carnation (Dianthus caryophyllus L.). Mol. Breed. 1999, 5, 367-375. [CrossRef]

45. Bovy, A.; Van Den Berg, C.; De Vrieze, G.; Thompson, W.F.; Weisbeek, P.; Smeekens, S. Light-Regulated Expression of the Arabidopsis thaliana Ferredoxin Gene Requires Sequences Upstream and Downstream of the Transcription Initiation Site. Plant Mol. Biol. 1995, 27, 27-39. [CrossRef] [PubMed]

46. Dickey, L.; Gallo-Meagher, M.; Thompson, W. Light Regulatory Sequences are Located within the $5^{\prime}$ Portion of the Fed-1 Message Sequence. EMBO J. 1992, 11, 2311-2317. [CrossRef] [PubMed] 
47. Okayama, T.; Furukawa, H.; Okamura, K.; Murase, H. The Effect of Photoperiod on $\beta$-Glucuronidase gene Expression under Control CaMV-35S Promoter in Transgenic Lettuce. Environ. Control. Biol. 2010, 48, 1-8. [CrossRef]

48. Saidi, Y.; Schaefer, D.G.; Goloubinoff, P.; Zrÿd, J.-P.; Finka, A. The CaMV 35S Promoter Has a Weak Expression Activity in Dark Grown Tissues of Moss Physcomitrella patens. Plant Signal. Behav. 2009, 4, 457-459. [CrossRef]

49. Ehlenfeldt, M.K.; Ortiz, R. Evidence on the Nature and Origins of Endosperm Dosage Requirements in Solanum and Other Angiosperm Genera. Sex. Plant Reprod. 1995, 8, 189-196. [CrossRef]

50. Nilsson, E. Some experiments with tetraploid tomatoes. Hereditas 1950, 36, 181-204. [CrossRef]

51. Ren, B.; Cam, H.; Takahashi, Y.; Volkert, T.; Terragni, J.; Young, R.A.; Dynlacht, B.D. E2F integrates cell cycle progression with DNA repair, replication, and G2/M checkpoints. Genes Dev. 2002, 16, 245-256. [CrossRef]

52. Cao, X.; Wang, H.; Zhuang, D.; Zhu, H.; Du, Y.; Cheng, Z.; Cui, W.; Rogers, H.J.; Zhang, Q.; Jia, C.; et al. Roles of MSH2 and MSH6 in cadmium-induced G2/M checkpoint arrest in Arabidopsis roots. Chemosphere 2018, 201, 586-594. [CrossRef] 